\title{
The pseudodisaccharides: a novel class of group I intron splicing inhibitors
}

\author{
Jeff Rogers* and Julian Davies \\ Department of Microbiology and Immunology, University of British Columbia, Vancouver, B.C., \\ V6T 1 Z3 Canada
}

Received August 10 ,1994; Revised and Accepted October 21, 1994

\begin{abstract}
Lysinomicin, a naturally-occurring pseudodisaccharide, inhibits translation in prokaryotes. We report that lysinomicin (and three related compounds) are able to inhibit the self-splicing of group I introns, thus identifying pseudodisaccharides as a novel class of group I intron splicing inhibitors. Lysinomicin inhibited the self-splicing of the sunY intron of phage T4 with a $K_{1}$ of $8.5 \mu \mathrm{M}(+/-5 \mu \mathrm{M})$ and was active against other group I introns. Inhibition was found to be competitive with the substrate guanosine, unlike aminoglycoside antibiotics, which act non-competitively to inhibit the splicing of group I introns. Competitive inhibitors of group I intron splicing known to date all contain a guanidino group that was thought to be required for inhibition; lysinomicin lacks a guanidino group.
\end{abstract}

\section{INTRODUCTION}

The sunY group I intron of phage T4 undergoes a self-splicing reaction similar to that of the LSU rRNA intron of Tetrahymena thermophila; splicing in vitro involves two consecutive transesterification reactions following the binding of guanosine to the RNA. The first step is initiated by the $3^{\prime} \mathrm{OH}$ of guanosine, which attacks the phosphorus atom at the $5^{\prime}$ splice site and forms a $3^{\prime}, 5^{\prime}$ phosphodiester bond with the first nucleotide in the intron. In the second step, the free $3^{\prime}$ hydroxyl group of the $5^{\prime}$ exon attacks the phosphorus atom at the $3^{\prime}$ splice site. This reaction results in the ligation of the exons and the release of the linear intron (1). Guanosine (and it's derivatives) interact with the intron RNA at the guanosine binding site by hydrogen bonding with the RNA. To determine the functions important for the binding and action of the substrate, analogues of guanosine were tested for their ability to compete with guanosine at the active site. It was proposed that there are four hydrogen bonds between guanosine and group I intron RNA, with the guanidino group of guanosine being responsible for three of these (2). The first competitive inhibitors of group I intron splicing, deoxy- and dideoxyguanosine (3), were found to have $K_{i}$ 's of 1.1 and 5.4 $\mathrm{mM}$ respectively. Arginine (4) and streptomycin (5) were also found to competitively inhibit group I intron splicing at millimolar concentrations; inhibition was accredited to the guanidino groups in these molecules.

The aminoglycoside antibiotics of the neomycin, gentamicin and kanamycin families are also inhibitors of group I intron splicing, but inhibit splicing non-competitively with 1000 -fold higher affinity compared to the guanosine analogues; these aminoglycosides do not contain a guanidino group $(6,7)$. The sites of interaction of the aminoglycoside antibiotics have been footprinted on both ribosomal RNA (8) and group I intron RNA (9). The interaction between RNA and aminoglycosides suggests a common mechanism for splice-site selection during group I intron splicing and decoding during translation (10). The peptides of the viomycin-tuberactinomycin class are another group of antibiotics which competitively inhibit the splicing of group I introns (11). They are basic cyclic peptides which contain guanidino groups and inhibit prokaryotic protein synthesis by preventing initiation and by blocking translocation. Interestingly, viomycin binds both ribosomal subunits, but most likely binds to the 30S subunit at the A site since viomycin resistant strains of mycobacteria are also resistant to kanamycin (12). The peptide antibiotics are the most potent competitive inhibitors of splicing identified to date, with viomycin inhibiting with a $K_{i}$ of approximately $17 \mu \mathrm{M}$ (for the $\mathrm{T} 4$ phage-derived $t d$ intron).

We describe here the interaction between group I intron RNA and a new group of antibiotics, the pseudodisaccharides. Lysinomicin (LM) (Fig. 1a), an antibiotic produced by Micromonospora pilospora was found to inhibit competitively the splicing of the sunY intron of phage T4 with a $\mathrm{K}_{\mathrm{i}}$ of $8.5 \mu \mathrm{M}$ $(+/-5 \mu \mathrm{M})$. LM shows antibiotic activity against several bacterial species(13); due to their structural similarity (Fig. 1b) it has been proposed that LM acts in a similar manner to fortimicin. Fortimicin A is known to inhibit prokaryotic protein synthesis and was found to prevent the dissociation of $70 \mathrm{~S}$ ribosomes (14).

\section{MATERIALS AND METHODS}

Bacterial strains and plasmids

Plasmid DNA was prepared by alkaline lysis and purified by cesium chloride ultracentrifugation. The plasmids containing the 
A

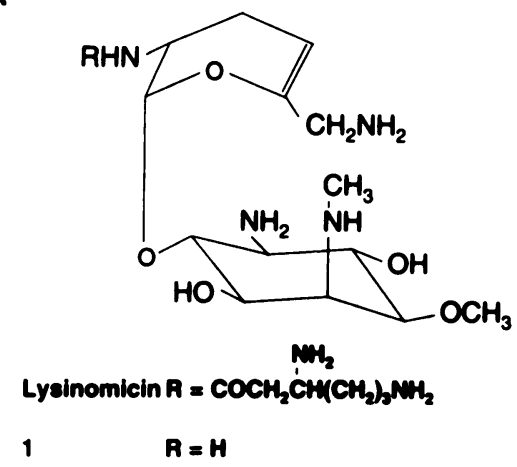

B

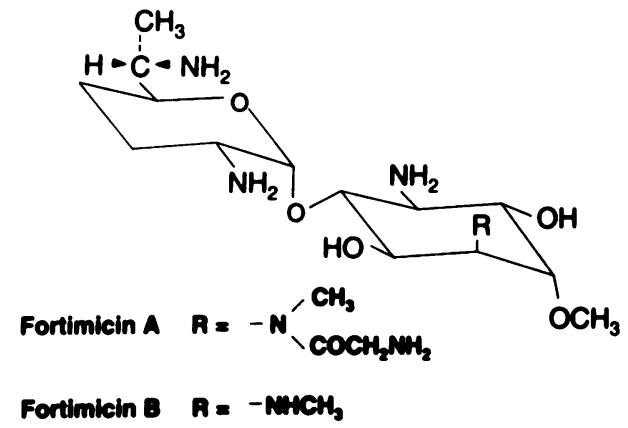

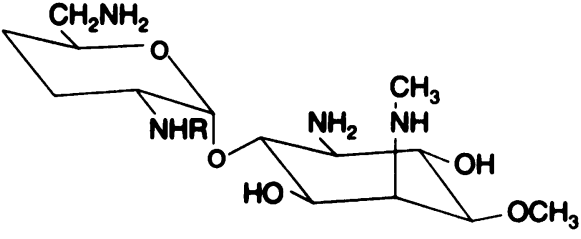

$2 \quad \mathrm{~A}=\mathrm{H} \quad \mathrm{MH}_{2}$

$\left.3 \quad \mathrm{~A}=\mathrm{COCH}_{2} \mathrm{CHMCH}_{2}\right)_{3} \mathrm{NH}_{2}$

C

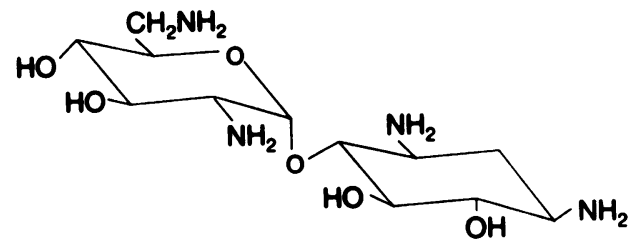

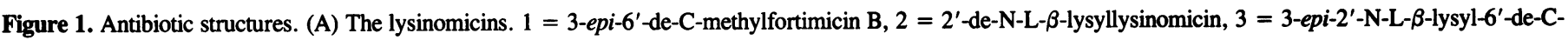
methylfortimicin B. (B) Fortimicin A and B. (C) Neamine.

introns were pSYC 1.3 (sunY intron - from F.Michel) and pTTIA3-T7 (Tetrahymena intron - from T.Cech). For in vivo studies of LM action, E.coli strain JM101 was transformed separately with two plasmids containing 16S rRNA methyltransferases: 1) pLST314 (gen ${ }^{\mathrm{r}}$, $\operatorname{tob}^{\mathrm{r}}$ and $\left.\operatorname{kan}^{\mathrm{r}}\right)(15)$ and 2) pUT172 (neor, tob ${ }^{r}$ and $\left.\operatorname{kan}^{r}\right)(16)$.

\section{In vitro splicing assays}

Purified DNA of intron-containing plasmids was linearized with EcoR1. Transcription ( $2 \mu \mathrm{g}$ DNA) was performed in a total volume of $40 \mu \mathrm{l}$ at $37^{\circ} \mathrm{C}$ for $1 \mathrm{~h}$ in $0.75 \times$ Stratagene T7 RNA polymerase buffer (the nucleotide to magnesium ratio was maintained at approximately 1.6 which prevents splicing during transcription), plus $25 \mathrm{mM}$ DTT (final concentration), $3 \mathrm{mM}$ of GTP, UTP, ATP, $0.5 \mathrm{mM}$ CTP, 100 units T7 RNA polymerase (Gibco BRL), and $80 \mu \mathrm{Ci} \alpha\left[{ }^{35} \mathrm{~S}\right]-\mathrm{CTP}$ (Stratagene). The reaction mixture was separated by electrophoresis on $5 \%$ polyacrylamide/7 M urea. Bands containing precursor RNA were cut out and eluted overnight $\left(37^{\circ} \mathrm{C}\right.$ with shaking) in $400 \mu$ l of elution buffer (2.5 mM EDTA, 0.3 M NH $4 \mathrm{NAc}_{4} 0.1 \%$ SDS and 10 $\mathrm{mM}$ Tris $-\mathrm{HCl} \mathrm{pH}$ 7.4). The resulting mixture was filtered, ethanol precipitated and resuspended in diethyl pyrocarbonate treated water.

For splicing reactions, 20000 c.p.m. (about $50 \mathrm{ng}$ ) of RNA was denatured by heating at $95^{\circ} \mathrm{C}$ for $45 \mathrm{~s}$ and incubated for $5 \mathrm{~min}$ in splicing buffer $(40 \mathrm{mM}$ Tris $-\mathrm{HCl}$ pH $7.5,5 \mathrm{mM}$ $\mathrm{MgCl}_{2}, 0.4 \mathrm{mM}$ spermidine) supplemented with $50 \mathrm{mM} \mathrm{NH} \mathrm{mLl}_{4}$ for the sunY intron and $200 \mathrm{mM} \mathrm{NaCl}$ for the Tetrahymena intron. Total volume of the splicing reaction was $10 \mu \mathrm{l}$. Splicing was initiated by the addition of guanosine, however, when drugs were being tested they were added immediately before guanosine. Reactions were for $10 \mathrm{~min}$ at 37 degrees, unless otherwise stated, and were stopped by the addition of $40 \mu \mathrm{l}$ of stop solution (2.5 mM EDTA, $0.1 \mathrm{mg} / \mathrm{ml}$ yeast tRNA), ethanol precipitated with $0.3 \mathrm{M} \mathrm{NaOAc} / \mathrm{EtOH}$, resuspended in loading dye, denatured at 95 degrees for $2 \mathrm{~min}$ and separated by electrophoresis.

\section{Kinetic studies}

Kinetic measurements were determined at the indicated substrate and antibiotic concentrations as previously described (17), with the following exceptions. Spliced products were separated by electrophoresis, autoradiographed and band densities quantitated on a densitometer (in duplicate). Spliced products were compared to a positive control (100 $\mu \mathrm{M}$ GTP for 10 minutes) present on every gel and plotted against time to calculate the initial velocity of the reaction. The Lineweaver-Burk slopes (1/Vo vs 1/[GTP]) were plotted against $L M$ concentration to provide the $K_{i}$ value (the $\mathrm{X}$-intercept). Each reaction was repeated three times at indicated antibiotic and GTP concentrations and all values were taken from reactions during the linear range.

Activity of lysinomicin against aminoglycoside resistant $\boldsymbol{E}$.coli JM101 and plasmid-containing derivatives were grown in LB medium and supplemented with $100 \mu \mathrm{g} / \mathrm{ml}$ ampicillin where 

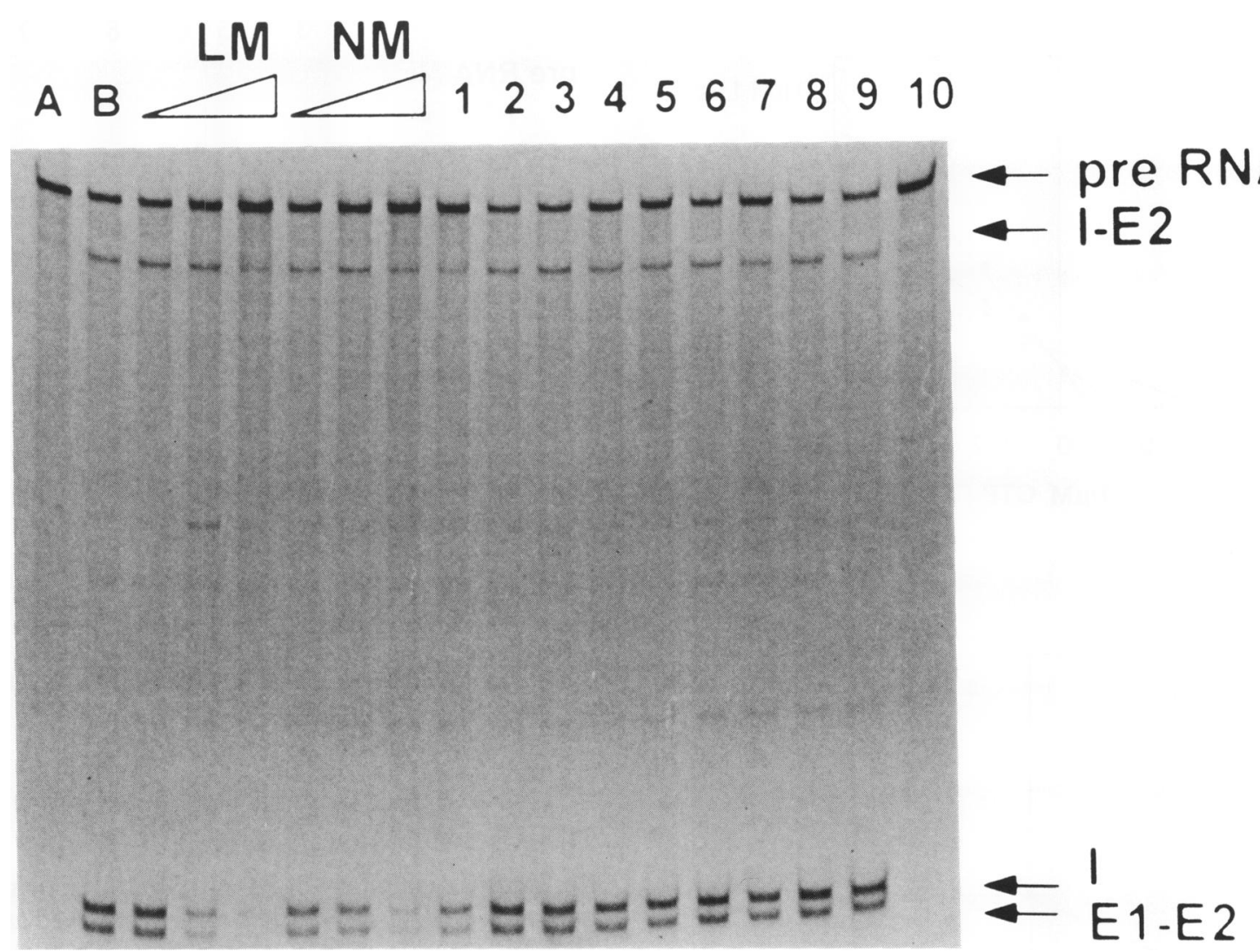

Figure 2. Binding of TFO to EcoRI-digested pCR12713Nef plasmid. Lane 1: $6 \mathrm{nCi}$ of [ $\left.{ }^{125} \mathrm{I}\right] \mathrm{TFO}$ in TA buffer (binding conditions); lane 2: $60 \mathrm{nCi}$ of [ $\left.{ }^{125} \mathrm{I}\right] \mathrm{TFO}$ in TA buffer; lane 3: $60 \mathrm{nCi}$ of [ $\left.{ }^{125} \mathrm{I}\right] \mathrm{TFO}$ in TE buffer (nonbinding conditions); lane 4: $60 \mathrm{nCi}$ of $\left[{ }^{32} \mathrm{P}\right] \mathrm{TFO}$ in TA buffer; lane 5: $60 \mathrm{nCi}$ of $\left[{ }^{32} \mathrm{P}\right] \mathrm{TFO}$ in TE buffer. Length of the fragments in base pairs is shown on the left.

indicated. Minimal inhibitory concentrations were determined by the dilution method, using 2-fold serial dilutions of antibiotics ranging in concentration from $2.5 \mathrm{mg} / \mathrm{ml}$ to $0.25 \mu \mathrm{g} / \mathrm{ml}$. Cultures were grown in 96 well microtiter plates due to the limited amount of each antibiotic available.

\section{RESULTS}

\section{Pseudodisaccharides competitively inhibit group I intron splicing in vitro}

Several pseudodisaccharides were screened for their ability to inhibit the splicing of the sunY intron (Fig. 2). LM and neamine (NM) effectively inhibited the reaction and therefore qualify pseudodisaccharides as a novel class of group I intron splicing inhibitors. Inhibition of splicing by LM was detected at a concentration of $25 \mu \mathrm{M}$ and complete inhibition was seen at 100 $\mu \mathrm{M}$. NM inhibited between $100 \mu \mathrm{M}$ and $200 \mu \mathrm{M}$. None of the other pseudodisaccharides tested showed significant activity [istamycin A (lane 1) weakly inhibits splicing] including fortimicin A (lane 8), which is closely related in structure to LM. This illustrates the specificity of lysinomicin inhibition of group I intron splicing. To test whether or not inhibition was competitive with GTP, varying concentrations of $\operatorname{LM}(0,10,20 \mu \mathrm{M})$ were incubated for various times (0-6 min) with $2,3,5$ and $10 \mu \mathrm{M}$ GTP. The $\mathrm{K}_{\mathrm{m}}$ for the guanosine reaction with the sunY intron was found to be $2.6 \mu \mathrm{M}$, which is close to the previously determined value of $2 \mu \mathrm{M}$ (7). LM inhibition of group I intron splicing was reversed by increasing concentrations of guanosine (data not shown). Initial velocities were calculated and the results represented in a Lineweaver-Burk plot (Fig. 3a). Since all lines intersect near the $\mathrm{Y}$-intercept, we conclude that $\mathrm{LM}$ is a competitive inhibitor of splicing. Furthermore, when the slopes of the lines from the Lineweaver-Burk graph are plotted against LM concentration, the $X$-intercept reveals a $K_{i}$ for $L M$ inhibition of group I intron splicing of $8.5 \mu \mathrm{M}(+/-5 \mu \mathrm{M})$ (Fig. 3b).

Three compounds closely related to LM were screened for inhibition of group I intron splicing activity (Fig. 4). All three compounds were more active than LM, with 3-epi-6'-de-Cmethylfortimicin B (1) showing $50 \%$ inhibition at approximately $20 \mu \mathrm{M}, 2^{\prime}$-de-N-L- $\beta$-lysyllysinomicin (2) completely inhibiting splicing at $25 \mu \mathrm{M}$ and 3-epi-2'-N-L- $\beta$-lysyl-6'-de-Cmethylfortimicin B (3) inhibiting splicing $50 \%$ at approximately $30 \mu \mathrm{M}$. Compounds 1 and 2 lack the $\beta$-lysine residue present in LM and 3 (13) and both 1 and 2 inhibit at lower concentrations than LM or 3. This suggests that the $\beta$-lysine residue may hinder the ability of these molecules to bind group I intron RNA. 
$\mathbf{A}$

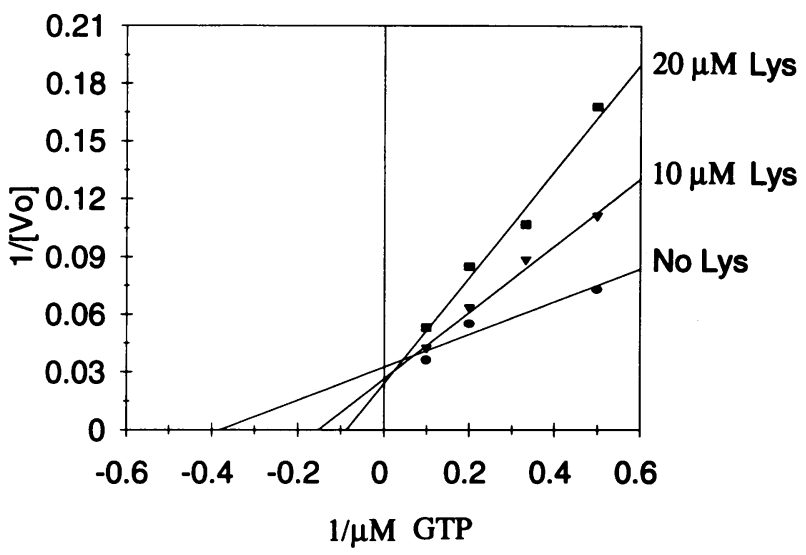

B

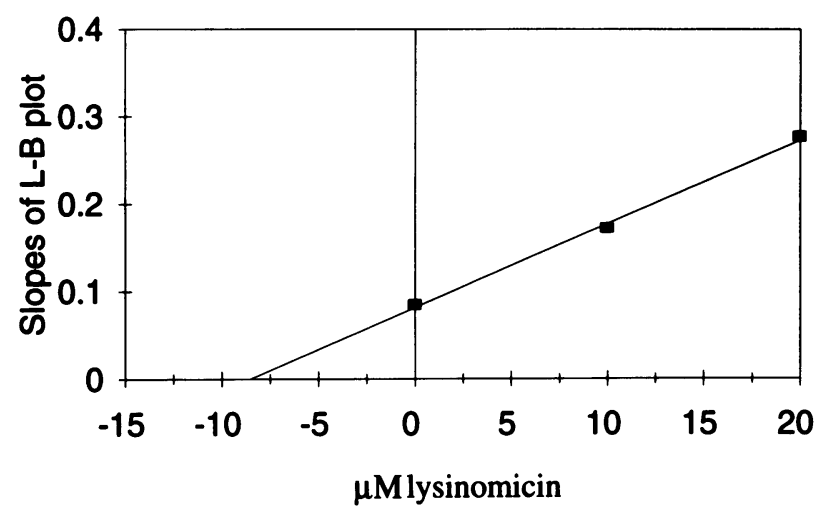

Figure 3. (A) Lineweaver-Burk plot of lysinomicin inhibition of $\operatorname{sun} Y$ group I intron splicing. Increased drug concentrations result in points which converge very near the $y$-axis, revealing a competitive inhibition mechanism. (B) Determination of the $\mathrm{K}_{\mathrm{i}}$ of lysinomicin inhibition. Plotting the slopes of the $\mathrm{L}-\mathrm{B}$ plot versus the concentration of lysinomicin gives a $\mathrm{K}_{\mathrm{i}}$ of $8.5 \mu \mathrm{M}(+/-$ $5 \mu \mathrm{M})$.

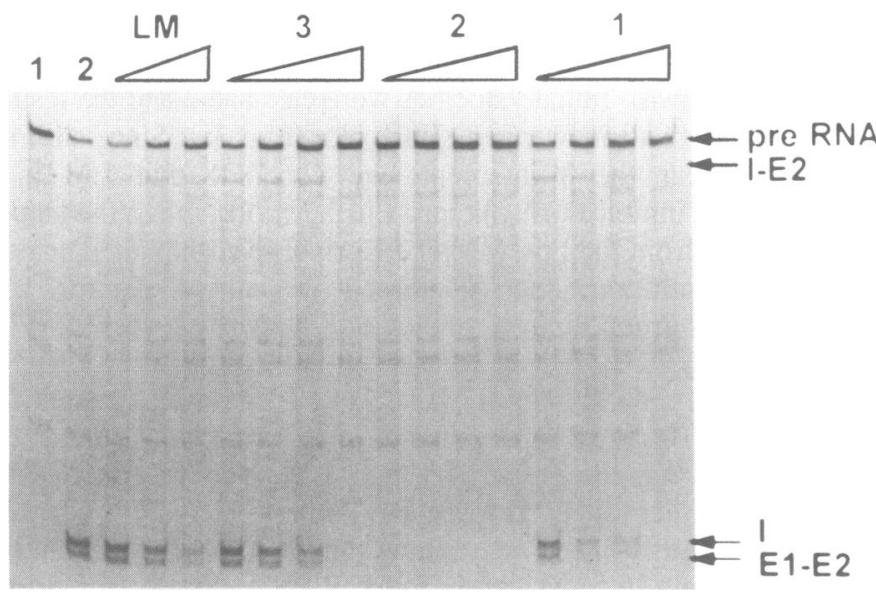

Figure 4. Inhibition of group I intron splicing by the lysinomicins. LM is present at 25,50 , and $100 \mu \mathrm{M}$ and 1,2 , and 3 at concentrations of $10,25,50$ and 100 $\mu \mathrm{M}$. All lanes containing antibiotic also have $2 \mu \mathrm{M}$ GTP present. Lane 1 contains no antibiotic or GTP and lane 2 contains $2.5 \mu \mathrm{M}$ GTP and no antibiotic.

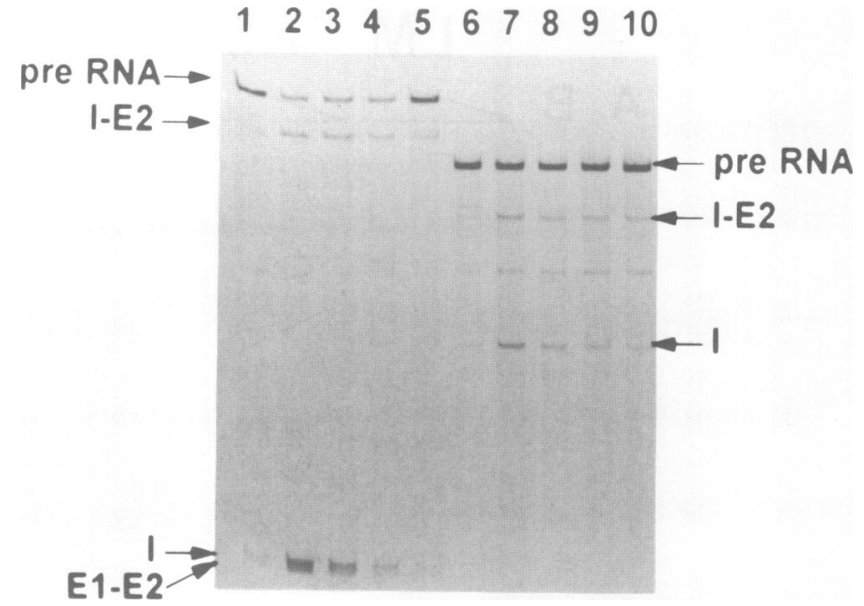

Figure 5. Inhibition of sunY and Tetrahymena intron splicing by LM. Lanes 1-5 - sunY intron. Lanes 6-10 - Tetrahymena intron. Lanes 1,6 - no GTP; lanes $2,7-2 \mu \mathrm{M}$ GTP; lanes $3,8-25 \mu \mathrm{M}$ LM plus $2 \mu \mathrm{M}$ GTP; lanes 4,9-50 $\mu \mathrm{M}$ LM plus $2 \mu \mathrm{M}$ GTP; lanes $5,10-100 \mu \mathrm{M}$ LM plus $2 \mu \mathrm{M}$ GTP.

\section{The effect of LM on other group I introns}

Competitive inhibitors of group I intron splicing bind at the guanosine binding site which is highly conserved among all group I introns (18). Therefore a competitive inhibitor of one intron should also inhibit the splicing of other group I introns. LM inhibits the splicing of the Tetrahymena and sunY introns at similar concentrations; approximately $50 \%$ inhibition occurring at $25 \mu \mathrm{M}$ lysinomicin (Fig. 5). LM was also found to inhibit the splicing of the $t d$ intron ( $t d$ delta P6-2) (7) and the group I intron of Bacillus phage SP01 (19), data not shown.

\section{Antimicrobial activity of lysinomicins}

To date, all antibiotics which inhibit group I intron splicing bind specifically to the A-site of the prokaryotic ribosome. The mechanism of action of LM had not been established, therefore we tested the ability of LM (and related compounds) to inhibit the growth of various E.coli strains sensitive and resistant to aminoglycosides which bind to the A-site of prokaryotic ribosomes. LM is closely related in structure to fortimicin (see Fig. 1b); it has been proposed that the two compounds act identically in inhibiting prokaryotic protein synthesis (13). Recently it has been shown that ribosomal methyltransferases that confer fortimicin resistance also result in gentamicin or neomycin resistance (20). Using two plasmids which encode 16S rRNA methyltransferases, we have examined resistance to the disaccharide antibiotics. pLST314 encodes a methyltransferase which methylates G-1405 in 16S rRNA thus conferring resistance to gentamicin, tobramycin and kanamycin (15). pUT172 encodes a methyltransferase which methylates A-1408 conferring neomycin, tobramycin and kanamycin resistance (16). JM101 is sensitive to all antibiotics and when harboring the plasmid pTZ18U, is resistant only to ampicillin. The methylation of A-1408 (pUT172 - neomycin ${ }^{r}$ ) resulted in lysinomycin resistance while methylation of G-1405 in JM101 (pLST314 gentamicin ${ }^{r}$ ) did not confer lysinomycin resistance; similar results were seen with 1 and 3 (Table 1). The results indicate that LM must bind to the same site on the ribosome as neomycin 
Table 1. Antimicrobial activity of the lysinomicins

\begin{tabular}{|c|c|c|c|c|c|c|c|}
\hline Strain & Plasmid & 165 rRMA Alteration & $\begin{array}{l}\text { MIC (ug/mL) } \\
\text { of neomycin) }\end{array}$ & $\begin{array}{l}\text { MIC (ug/mL) } \\
\text { of gentamicin }\end{array}$ & $\begin{array}{l}\text { MIC (ug/mL) } \\
\text { of bysinomicin }\end{array}$ & $\begin{array}{l}\text { Mic of } \\
\text { (2) }\end{array}$ & $\begin{array}{l}\text { MiC of } \\
(3)\end{array}$ \\
\hline JM101 & none & none & 2 & 1 & 1 & 13 & 13 \\
\hline JM101 (pTZ18U) & Resistant to Ap & none & 2 & 1 & 1 & 13 & 13 \\
\hline JM101 (pLST314) & $\begin{array}{l}\text { Contains a methyttransferase } \\
\text { Resistant to Ap, Gen, Kan \& Tob }\end{array}$ & G-1405 methylated & 5 & 1250 & 2 & 16 & 16 \\
\hline JM101 (pUT172) & $\begin{array}{l}\text { Contains a methyltransferase } \\
\text { Resistant to Ap, Neo, Kan \& Tob }\end{array}$ & A-1408 methylated & 150 & 40 & 50 & 60 & 500 \\
\hline $\begin{array}{l}50 \% \text { Group I Intron } \\
\text { Splicing Inhibition }\end{array}$ & & & & & 50 uM & $<10 u M$ & $30 \mathrm{um}$ \\
\hline
\end{tabular}

MIC $=$ minimum inhibitory concentration $(\mu \mathrm{g} / \mathrm{ml}) . \mathrm{Ap}=$ ampicillin, Gen $=$ gentamicin, $\mathrm{Kan}=$ kanamycin $\mathrm{A}, \mathrm{Tob}=$ tobramycin, Neo $=$ neomycin, (2) = $2^{\prime}$-de-N-L- $\beta$-lysyllysinomicin, (3) = 3-epi-2'-N-L- $\beta$-lysyl-6'-de-C-methylfortimicin B.

(close to the sites that bind kanamycin and tobramycin) and that pseudodisaccharides of this class inhibit prokaryotic protein synthesis by binding to the $30 \mathrm{~S}$ subunit. This provides further confirmation of the functional correspondence between the Asite of the $30 \mathrm{~S}$ subunit and group I introns.

\section{DISCUSSION}

The pseudodisaccharide antibiotics, which we show to interact with 16S rRNA at a similar site as some aminoglycosides (based on resistance mechanisms), inhibit group I intron splicing by competing with guanosine binding at the cofactor binding site. LM is the most effective competitive inhibitor of group I intron splicing currently known (neomycin binds non-competitively). Previously, competitive inhibitors of group I intron splicing [deoxy and dideoxyguanosine (3), arginine (4), streptomycin (5) and the tuberactinomycins (11)] were thought to compete with guanosine because they contained guanidino (or pseudoguanidino) groups. Lysinomycin is a competitive inhibitor which lacks a guanidino or similar group. All pseudodisaccharides found to inhibit splicing are similar in structure, except neamine which was a monosubstituted 2-deoxystreptamine (Fig. 1c). All other compounds were monosubstituted fortamines. Neamine is derived by hydrolysis of neomycin, which is a potent inhibitor of group I intron splicing $\left(\mathrm{K}_{\mathrm{i}}=0.5 \mu \mathrm{M}\right)(7)$.

The tuberactinomycins are cyclic peptide antibiotics which inhibit splicing competitively and it has been proposed that their $\beta$-lysine side chain binds to the RNA backbone and increases the ability of these compounds to bind group I intron RNA (11). Because 1 and 2 inhibit group I intron splicing and lack the $\beta$ lysine side chain, it would appear that this group plays no significant role in the lysinomicin/intron RNA interaction. Due to their structural simplicity, these pseudodisaccharides will be invaluable in structure/function studies of interactions between catalytically active RNA and small molecules. The pseudodisaccharides competitively inhibit the splicing of the sunY intron and also inhibit several other group I introns at similar concentrations. The fact that these molecules compete for the guanosine binding site of different group I introns, supports the notion that the three-dimensional shape of the guanosine binding sites of all group I introns are highly conserved. Group I introns, other ribozymes, and the RRE sequence of HIV (21) all interact with similar antibiotics, suggesting the presence of antibiotic binding motifs in these RNAs. Since all these antibiotics also bind to the A-site of 30S rRNA it has been suggested that there is an evolutionary link between these two types of RNA (22). This is consistent with the notion that antibiotics (secondary metabolites) were the functional precursors of modern ribosomal proteins (23) which may explain why the same antibiotics act on both 16S rRNA and group I introns. The demonstration that LM (which we show to be an inhibitor of translation at the A site) inhibits group I intron splicing strengthens the suggestion that naturally occurring inhibitors of ribozymes may prove to be useful leads in the search for novel inhibitors of pathogenic fungi and viruses.

\section{ACKNOWLEDGEMENTS}

We would like to thank Renee Schroeder, Herbert Wank and Barbara Streicher for encouragement and discussions. We also want to thank Uwe von Ahsen for advice on technical aspects. James McAlpine generously provided lysinomicin and related pseudodisaccharides. This research was funded by the Natural Science and Engineering Research Council.

\section{REFERENCES}

1. Cech, T.R. (1990) Annu. Rev. Biochem. 59, 543-568.

2. Bass, B.L. and Cech, T.R. (1984) Nature 308, 820-826.

3. Bass, B.L. and Cech, T.R. (1986) Biochemistry 25, 4473-4477.

4. Yarus, M. (1988) Science 240, 1751-1758.

5. von Ahsen, U. and Schroeder, R. (1991) Nucl. Acids Res. 19, $2261-2265$.

6. von Ahsen, U., Davies, J. and Schroeder, R. (1991) Nature 353, 368-370.

7. von Ahsen, U., Davies, J. and Schroeder, R. (1992) J. Mol. Biol. 226, 935-941.

8. Moazed, D. and Noller H.F. (1987) Nature 327, 389-394.

9. von Ahsen, U. and Noller H.F. (1993) Science 260, 1500-1503.

10. Schroeder, R., Streicher, B., and Wank, H. (1993) Science 260, 1443-1444.

11. Wank, H., Rogers, J., Davies, J. and Schroeder, R. (1994) J. Mol. Biol. 236, $1001-1010$. 
4988 Nucleic Acids Research, 1994, Vol. 22, No. 23

12. Tsukamura, M. and Mizuno, S. (1980) Microbiol. Immunol. 24, 777-787.

13. Kurath, P., Rosenbrook, W.,Jr., Dunnigan, D.A. and McAlpine, J.B. (1984) J. Antibiotics 37, 1130-1143.

14. Moreau, N., Jaxel, C. and Le Goffic, F. (1984) Antimicrobial Agents and Chemotherapy 26, 857-862.

15. Holmes, D.J. and Cundliffe, E. (1991) Molec. Gen. Genet. 229, 229-237.

16. Holmes, D.J., Drocourt, D., Tiraby, G. and Cundliffe, E. (1991) Gene 102, 19-26.

17. Schroeder, R., von Ahsen, U. and Belfort, M. (1991) Biochemistry 30, 3295-3303.

18. Michel, F., and Westhof, E. (1990) J. Mol. Biol. 216, 585-610.

19. Goodrich-Blair, H., Scarlato, V., Gott, J.M., Xu, M. and Shub, D.A. (1990) Cell 63, 417-424.

20. Ohta, T. and Hasegawa, M. (1993) Gene 127, 63-69.

21. Zapp, M. L., Stern, S., and Green M.R. (1993) Cell 74, 969-978.

22. Davies, J. (1990) Molec. Microbiol. 4, 1227-1232 .

23. Davies, J., von Ahsen, U. and Schroeder, R. (1993) The RNA World, pp. 185-204, Cold Spring Harbor Laboratory Press, Cold Spring Harbor, NY. 